\title{
Reply: Cytotoxic effect of disulfiram/copper on human glioblastoma cell lines and ALDH-positive cancer-stem-like cells
}

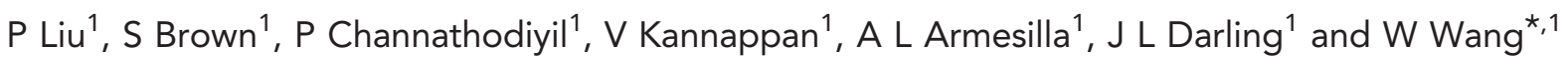 \\ ${ }^{1}$ Research Institute in Healthcare Science, School of Applied Sciences, University of Wolverhampton, Wolverhampton WV1 1LY, UK
}

Sir,

We thank Dr Cvek (2013), this issue, for his interest in our study and providing very important information in his letter. In order to apply disufiram (DS) in cancer treatment, we would address the following issues.

Our studies suggest that copper is essential for anticancer activity of DS in vitro (Yip et al, 2011; Liu et al, 2012) and in vivo (unpublished data). Disufiram is promptly converted to diethyldithiocarbamate (DDC, ditiocarb), which chelates copper (II) forming a DDC-Cu complex, an active anticancer compound. Our collaborators at the Shenyang Pharmaceutical University, China, have observed complete remission in some breast cancer patients following oral administration of DS and copper gluconate (Tang X, personal communication). No side effect has been observed from these patients. This is highly in line with Dufour's observation (Dufour et al, 1993). Although copper was not included in Dufour's trial, ditiocarb may chelate copper in serum and cancer cells. These findings provide us with very strong clinical evidence for repositioning of DS in cancer therapeutics.

Although the existence of CSCs is still arguable, it is widely accepted that the cells with CSCs characters are highly resistant to chemo- and radiotherapy and are the source of cancer recurrence. Therefore, development of anti-CSCs agents becomes 'hotspot' in anticancer drug research and development. Recently, emerging evidence indicates that DS eradicates CSCs and reverses chemoresistance (Yip et al, 2011; Hothi et al, 2012; Liu et al, 2012; Triscott et al, 2012). The CSCs express high levels of Pgp protein with high MDR activity. Our unpublished data show that DS inhibits Pgp expression and reverse resistance in a paclitaxel-resistant breast cancer cell line. Considering its apparently low/non toxicity, DS may be used in combination with conventional anticancer drug as a chemo- or/and radio-sensitizer to target CSCs without adding general toxicity burden on cancer patients.

The metabolisms and clinical pharmacology of DS are well understood. However, its potential application in cancer treatment is still hampered by its currently available oral formulation.
Disufiram is extremely unstable in acidic gastric environment and is also rapidly degraded in blood stream. The blood concentration of DS or DDC after oral administration of a $500 \mathrm{mg}$ dose is below the limit of detection (Johansson, 1992). We are presently examining encapsulated forms of DS. The preliminary animal study data indicate that encapsulated DS significantly improves the anticancer activity of DS. Once an optimum formulation of DS becomes available, robustly designed clinical trials will need to be rapidly developed to test the clinical utility of this promising approach to cancer treatment.

\section{REFERENCES}

Cvek B (2013) Comment on 'Cytotoxic effect of disulfiram/copper on human glioblastoma cell lines and ALDH-positive cancer-stem-like cells'. $\mathrm{Br} \mathrm{J}$ Cancer; e-pub ahead of print 22 January 2013; doi:10.1038/bjc.2013.18.

Dufour P, Lang JM, Giron C, Duclos B, Haehnel P, Jaeck D, Jung JM, Oberling F (1993) Sodium dithiocarb as adjuvant immunotherapy for high risk breast cancer: a randomized study. Biotherapy 6: 9-12.

Hothi P, Martins TJ, Chen LP, Deleyrolle L, Yoon JG, Reynolds B, Foltz G (2012) High-throughput chemical screens identify disulfiram as an inhibitor of human glioblastoma stem cells. Oncotarget 3: 1124-1136.

Johansson B (1992) A review of the pharmacokinetics and pharmacodynamics of disulfiram and its metabolites. Acta Psychiatr Scand Suppl 369: 15-26.

Liu P, Brown S, Goktug T, Channathodiyil P, Kannappan V, Hugnot JP, Guichet PO, Bian X, Armesilla AL, Darling JL, Wang W (2012) Cytotoxic effect of disulfiram/copper on human glioblastoma cell lines and ALDHpositive cancer-stem-like cells. Br J Cancer 107: 1488-1497.

Triscott J, Lee C, Hu K, Fotovati A, Berns R, Pambid M, Luk M, Kast RE, Kong E, Toyota E, Yip S, Toyota B, Dunn SE (2012) Disulfiram, a drug widely used to control alcoholism, suppresses self-renewal of glioblastoma and overrides resistance to temozolomide. Oncotarget 3(10): 1112-1123.

Yip NC, Fombon IS, Liu P, Brown S, Kannappan V, Armesilla AL, Xu B, Cassidy J, Darling JL, Wang W (2011) Disulfiram modulated ROS-MAPK and NFkB pathways and targeted breast cancer cells with cancer stem cell like properties. Br J Cancer 104: 1564-1574. 